\title{
Cryoablation of Early-Stage Breast Cancer: Work-in-Progress Report of a Multi-Institutional Trial
}

\author{
Michael S. Sabel, MD, Cary S. Kaufman, MD, Pat Whitworth, MD, Helena Chang, MD, PhD, \\ Lewis H. Stocks, MD, PhD, Rache Simmons, MD, and Michael Schultz, MD
}

\begin{abstract}
Background: With recent improvements in breast imaging, our ability to identify small breast tumors has markedly improved, prompting significant interest in the use of ablation without surgical excision to treat early-stage breast cancer. We conducted a multi-institutional pilot safety study of cryoablation in the treatment of primary breast carcinomas.

Methods: Twenty-nine patients with ultrasound-visible primary invasive breast cancer $\leq 2.0 \mathrm{~cm}$ were enrolled. Twenty-seven (93\%) successfully underwent ultrasound-guided cryoablation with a tabletop argon gas-based cryoablation system with a double freeze/thaw cycle. Standard surgical resection was performed 1 to 4 weeks after cryoablation. Patients were monitored for complications, and pathology data were used to assess efficacy.

Results: Cryoablation was successfully performed in an office-based setting with only local anesthesia. There were no complications to the procedure or postprocedural pain requiring narcotic pain medications. Cryoablation successfully destroyed $100 \%$ of cancers $<1.0 \mathrm{~cm}$. For tumors between 1.0 and $1.5 \mathrm{~cm}$, this success rate was achieved only in patients with invasive ductal carcinoma without a significant ductal carcinoma-in-situ (DCIS) component. For unselected tumors $>1.5 \mathrm{~cm}$, cryoablation was not reliable with this technique. Patients with noncalcified DCIS were the cause of most cryoablation failures.

Conclusions: Cryoablation is a safe and well-tolerated office-based procedure for the ablation of early-stage breast cancer. At this time, cryoablation should be limited to patients with invasive ductal carcinoma $\leq 1.5 \mathrm{~cm}$ and with $<25 \%$ DCIS in the core biopsy. A multicenter phase II clinical trial is planned.
\end{abstract}

Key Words: Cryosurgery-Cryoablation-Breast cancer-Ablative therapies.

It is estimated that in 2004 there will be more than 215,000 cases of female breast cancer diagnosed in the United States, making it the most common malignant

\footnotetext{
Received August 8, 2003; accepted January 20, 2004.

From the Department of Surgery, University of Michigan Comprehensive Cancer Center, Ann Arbor, Michigan (MSS); the Department of Surgery, University of Washington, Bellingham Breast Center, Bellingham, Washington (CSK); the Nashville Breast Center, Nashville, Tennessee (PW); Revlon UCLA Breast Center, Los Angeles, California (HC); Department of Surgery, Executive Surgical Center, Raleigh, North Carolina (LHS); Department of Surgery, Weill Medical College of Cornell University, New York, New York (RS); and Surgery Center of Greater Baltimore, Owings Mills, Maryland (MS).

Address correspondence and reprint requests to: Michael S. Sabel, MD, University of Michigan, 3304 Cancer Center, 1500 East Medical Center, Ann Arbor, MI 48109-0932; Fax: 734-647-9647; E-mail: msabel@umich.edu.
}

Published by Lippincott Williams \& Wilkins (C) 2004 The Society of Surgical Oncology, Inc. tumor in women. ${ }^{1}$ The most striking influence on the treatment of breast cancer came after the demonstration that there was no difference in survival between breastconservation therapy and mastectomy. ${ }^{2}$ This shift in surgical therapy has resulted in a significant decrease in the morbidity and disfigurement associated with treatment, without a loss in survival.

A lumpectomy, however, is still an invasive procedure and leaves the patient with a scar and possible cosmetic defect in the breast. With improvements in imaging, cancers smaller than $1.0 \mathrm{~cm}$ are increasing in frequency. ${ }^{3}$ Therefore, there is intense interest in the possibility of ablating small cancers within the breast without excisional surgery. This not only would improve cosmetic outcomes, but also could greatly decrease operating room and anesthesia needs, recovery times, surgical complications, and health-care costs. Several methods 
are presently being investigated for the in situ ablation of breast cancer, including radiofrequency ablation, ${ }^{4-7}$ cryosurgery, ${ }^{8,9}$ laser interstitial therapy, ${ }^{10-17}$ high-intensity focused ultrasound, ${ }^{18-25}$ and focused microwave thermotherapy. ${ }^{26-29}$

Cryosurgery has been successfully used for the ablation of tumors in the liver, 30,31 prostate, ${ }^{32,33}$ and kidney ${ }^{34,35}$; the palliative treatment of locally advanced breast cancers ${ }^{36,37}$; and the treatment of breast fibroadenomas. ${ }^{38}$ The ability to clearly visualize the forming ice ball with ultrasound provides outstanding precision and control for this procedure. With the recent improvements in breast imaging, our ability to visualize, take biopsy samples from, and treat breast tumors has markedly improved. This has prompted significant interest in the use of cryoablation instead of surgical excision in the treatment of small early-stage breast cancer. Preclinical studies have demonstrated that $100 \%$ tumor kill is attainable with cryosurgery and that ultrasonography can accurately guide probe placement and monitor the development of the ice ball. ${ }^{8,9,39-41}$ On the basis of these results, we initiated a phase I multicenter trial of cryoablation followed by delayed surgical excision to determine the safety and feasibility of this treatment. Preliminary results from this trial reveal that cryoablation of early-stage breast cancer is extremely well tolerated and can be performed with minimal discomfort or morbidity. In addition, with proper patient selection, it can achieve $100 \%$ tumor ablation in most patients.

\section{MATERIALS AND METHODS}

\section{Cryoablative Procedure}

A tabletop argon gas-based cryoablation system (Visica Cryoablation System; Sanarus Medical, Pleasanton, CA), designed to create probe temperatures of $-160^{\circ} \mathrm{C}$, was used to treat all tumors in an outpatient setting (Fig. 1). Ultrasound guidance facilitates accurate placement of the probe in the center of the tumor. The cryoablation system creates an ice ball that rapidly engulfs the tumor plus a margin of apparently healthy tissue. In all cases, patients underwent a double freeze/ thaw cycle: a freeze followed by a passive thaw and then another freeze. This allows for osmotic shifts to occur at the cellular level that lead to enhanced destruction of the targeted tissue. ${ }^{42}$ An active thaw with helium gas warms the cryoprobe after the second freeze, permitting its rapid removal after the last cycle. Over the course of the trial, the freeze time was altered and the cryoprobe was modified. The initial probe was a 2.4-mm-diameter, air gapinsulated, sharp-tipped probe (11 cases). The next-generation cryoprobe was introduced into the study for cases

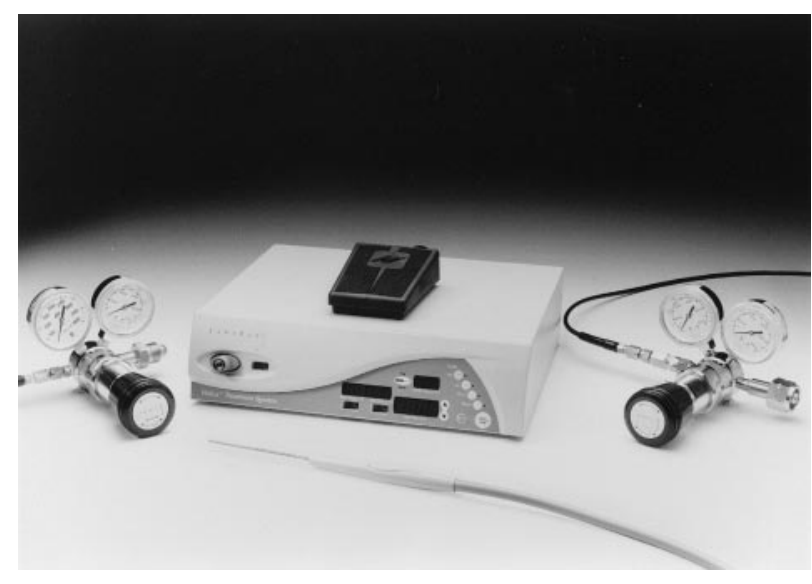

FIG. 1. Tabletop argon gas-based cryoablation system.

12 to 29 . It was a $2.7-\mathrm{mm}$-diameter, vacuum-insulated, trocar-tipped instrument that allowed cooling to occur only at its distal $4 \mathrm{~cm}$. The improved insulation on this probe allowed for elimination of skin protection techniques other than the injection of sterile saline between the skin and growing ice ball for lesions close to the skin. Before this probe was introduced, dripped sterile saline, moist gauze placed between the skin and probe, skin temperature monitoring, and an introducing trocar with cannula were additionally used for skin protection.

For the first 11 patients, the freeze time was $10 \mathrm{~min}$ utes at a $100 \%$ duty cycle (argon gas flowing $100 \%$ of the time for maximum cooling) regardless of tumor size. On the basis of experience treating fibroadenomas, ${ }^{38}$ this was subsequently altered so that freeze time was based on the maximum tumor diameter, as assessed by ultrasound, to avoid excessive freezing of uninvolved tissue around smaller lesions (Table 1). Each freeze cycle was split between a high freeze and a low freeze. During high freeze, the system operated at a 100\% duty cycle (argon flowed continuously), whereas during low freeze, it operated at a $10 \%$ duty cycle (argon gas flows for 1 second and is off for 9 seconds of every 10 -second period). This $10 \%$ duty cycle maintains cold temperatures within the ice ball while slowing the ice ball's overall growth. A passive thaw lasting 10 to 12 minutes (depending on the

TABLE 1. Cancer cryoablation

\begin{tabular}{cc}
\hline $\begin{array}{c}\text { Longest imaged cancer } \\
\text { diameter }(\mathrm{cm})\end{array}$ & $\begin{array}{c}\text { Freeze parameters (minutes at high } \\
\left.\text { freeze/minutes at low freeze }{ }^{a}\right)\end{array}$ \\
\hline$<1.0$ & $6 / 4$ \\
$1.0-1.3$ & $8 / 2$ \\
$1.4-1.8$ & $10 / 2$ \\
\hline
\end{tabular}

${ }^{a}$ Total treatment $=$ high/low freeze + passive thaw for total time of high/low freeze + repeat high/low freeze. 
cycle used) was interposed between the two freeze cycles, and an active thaw with helium gas was performed after the second freeze, thereby facilitating probe removal.

\section{Clinical Study}

Between March 2000 and February 2003, patients with primary invasive breast cancer at several participating institutions were offered an opportunity to participate in a clinical trial involving cryoablation followed by delayed surgical resection. To be considered for this trial, all patients had to have ultrasonographic evidence of a solitary breast mass measuring $\leq 2.0 \mathrm{~cm}$ in greatest dimension. The diagnosis of invasive breast cancer was made on large-core needle biopsy (LCNB). All standard histological parameters and immunohistochemical assessment of estrogen and progesterone receptors and HER-2/neu were established from the core biopsy before ablation. All participating patients signed written, informed consent that was approved by the institutional review board of their respective facilities.

Four early cryoablation cases were performed in outpatient surgery by using general anesthesia ${ }^{1}$ or intravenous sedation. ${ }^{3}$ All subsequent case ${ }^{25}$ were performed in an office-based setting without sedation, with the patient awake and alert throughout the procedure. The breast was prepared and draped in typical sterile fashion, and the breast tumor was identified by ultrasonography. Xylocaine was injected in the skin and along the projected path toward the center of the tumor. An 11-blade scalpel was used to make a 3-mm skin incision to allow placement of the cryoprobe (Fig. 2).

All procedures were performed under real-time ultrasound guidance. The probe was inserted through the center of the cancer, and the tip was advanced beyond the distal edge of the tumor to ensure equal treatment on both sides of the tumor in the longitudinal plane of the freeze zone (Fig. 3). Transverse ultrasound examination confirmed the central position of the cryoprobe within the tumor. Failure to adequately place the cryoprobe was considered a protocol violation. After central placement within the tumor was confirmed, the cryoablation procedure was performed as described previously. Skin appearance, ice ball size, and patient comfort were closely monitored during the procedure. Sterile normal saline was injected between the forming ice ball and skin whenever they were within $5 \mathrm{~mm}$ of each other (Fig. 4). After the second freeze cycle, the probe was actively thawed and removed, a sterile dressing was applied, and pressure was maintained according to the institution's standard for LCNB. Patients were instructed to look for transient ecchymosis, tenderness, edema, or a palpable mass in the

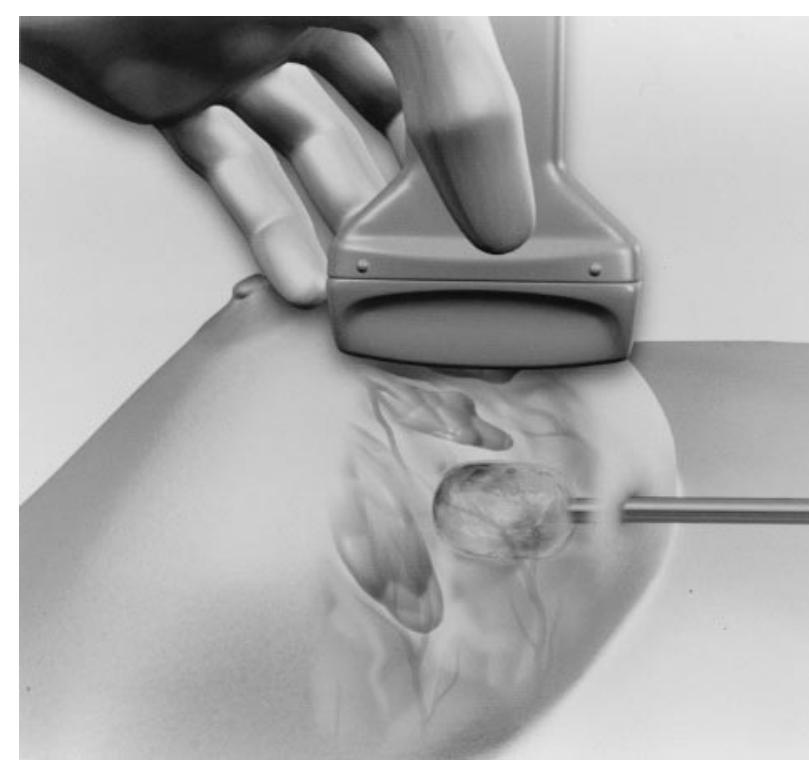

FIG. 2. Cryoablation of breast cancer. Ultrasound is used to monitor the creation of an ice ball, which engulfs the cancer, destroying the targeted area.

region of cryoablation and were asked to report all postprocedural symptoms.

Within 7 to 30 days of the cryoablation procedure, patients returned for their planned surgical treatment: either lumpectomy or mastectomy. Sentinel lymph node biopsy, when clinically indicated, was performed at the time of surgical resection. The excised breast specimen was sent for pathologic evaluation, where the margins were inked. The tumor was bisected centrally to grossly determine the dimensions of the region exposed to cryosurgery. Radial sections were then submitted for fixation and histopathological preparation with hematoxylin and

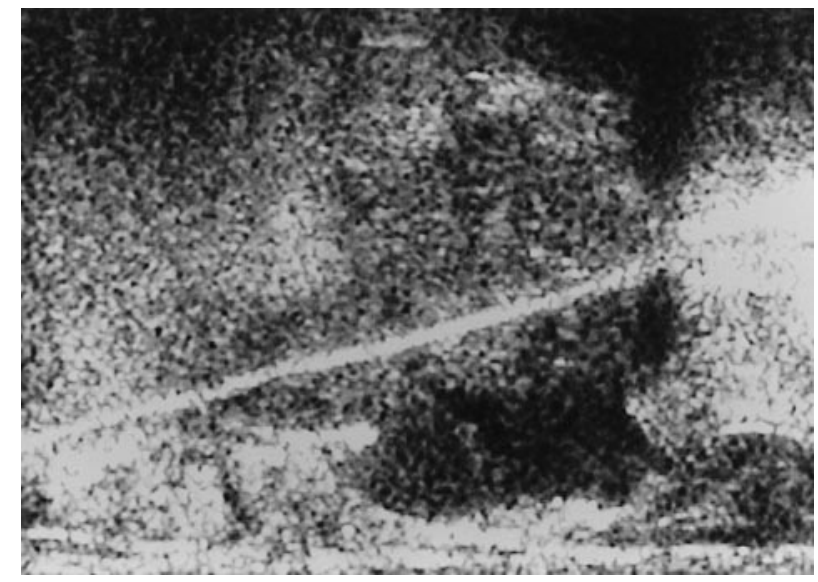

FIG. 3. Ultrasound image of the cryoprobe advanced through the center of the cancer. 


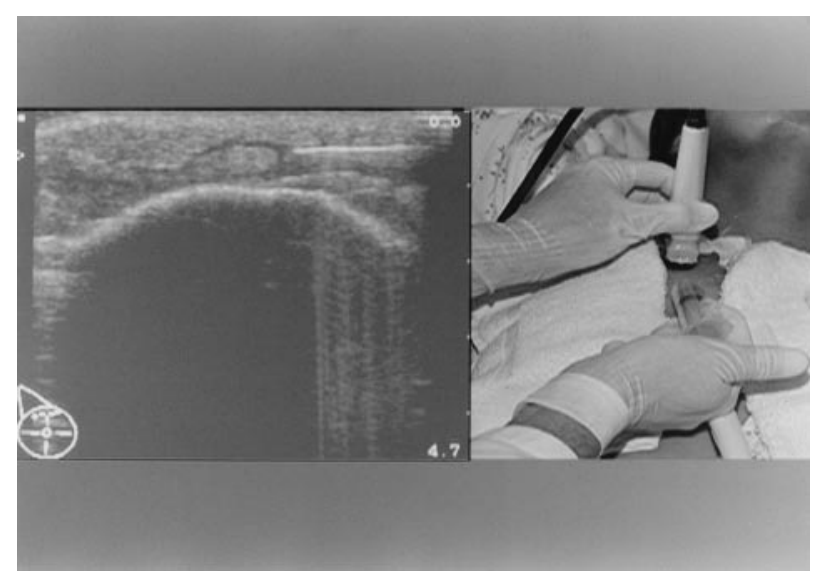

FIG. 4. Injection of saline between the ice ball and skin for skin protection during cryoablation.

eosin staining and were evaluated according to the routine of the individual institution. These sections were also assessed to determine the extent of microscopic destruction of the tumor. A successful ablation was defined as a complete $(100 \%)$ ablation of the clinically detectable tumor, including both invasive and in situ components.

\section{RESULTS}

Twenty-nine women participated in the study. The median age was 52.5 years (range, 34-77 years). The clinical characteristics of the patients are listed in Table 2. The mean greatest dimension of breast tumors was 1.2 $\pm .5 \mathrm{~cm}$ (range, $.6-2.0 \mathrm{~cm})$. Distance to the skin ranged from .2 to $2.0 \mathrm{~cm}$ (average, $1.1 \mathrm{~cm}$ ). The probe was successfully placed under ultrasound guidance in the center of the tumor in 27 (93\%) of 29 patients. In two cases, the cryoprobe could not be accurately placed within the tumor. Of the 27 women successfully treated,

TABLE 2. Tumor characteristics

\begin{tabular}{lc}
\hline \multicolumn{1}{c}{ Characteristic } & $\begin{array}{c}\text { No. of patients } \\
(\%)\end{array}$ \\
\hline Tumor size (greatest dimension; cm) & \\
$0-.5$ & $0(0 \%)$ \\
$.51-1.00$ & $11(41 \%)$ \\
$1.01-1.50$ & $9(33 \%)$ \\
$1.51-2.0$ & $7(26 \%)$ \\
Histology & $16(59 \%)$ \\
Invasive ductal carcinoma & $5(19 \%)$ \\
Invasive ductal carcinoma with DCIS & $3(11 \%)$ \\
Invasive lobular carcinoma & $2(7 \%)$ \\
Colloid carcinoma & $1(3 \%)$ \\
Medullary carcinoma & \\
\hline
\end{tabular}

DCIS, ductal carcinoma-in-situ. the first 10 patients were treated with 10-minute highfreeze cycles regardless of tumor size. The next 17 patients underwent tailored ablation with the high/low freezes previously described. Nine patients with tumors $>1.0 \mathrm{~cm}$ had two freeze cycles consisting of an 8 - or 10-minute high freeze and a 2-minute low freeze. Eight patients with tumors $<1.0 \mathrm{~cm}$ underwent two cycles consisting of a 6-minute high freeze and a 4-minute low freeze.

Continuous ultrasound monitoring documented the size of the ice ball forming around the cryoprobe. The mean dimensions (length $\times$ width $\times$ depth) of the ice balls after high-freeze cycles of 8 or 10 minutes was 4.8 $\pm .7 \mathrm{~cm} \times 3.38 \pm .6 \mathrm{~cm} \times 3.31 \pm .69 \mathrm{~cm}$. For high-freeze cycles of 6 minutes, the dimensions were 3.8 $\pm .5 \mathrm{~cm} \times 2.7 \pm .5 \mathrm{~cm} \times 2.7 \pm .4 \mathrm{~cm}$. The mean volume of the ice ball was $29.5 \pm 13.4 \mathrm{~mm}^{3}$ and $15.2 \pm$ $5.7 \mathrm{~mm}^{3}$, respectively.

Cryoablation was very well tolerated in all patients. Early procedures were performed in the operating room, but 25 procedures were performed in an office-based setting with only local anesthesia. These patients were awake and comfortable throughout the freeze-thawfreeze cycle, which takes approximately 30 minutes. No patients had postprocedural pain requiring narcotic pain medications, and there were no significant complications from the procedure.

All 27 successfully treated patients underwent lumpectomy an average of 14 days after the cryoablation (range, 6 to 30 days). Twenty-five of 27 patients had axillary staging by intraoperative lymph node mapping and sentinel lymph node biopsy performed at the same time. Four (16\%) of the 25 patients had a positive sentinel lymph node. The cryoablation had no effect on the subsequent interpretation of the sentinel lymph node.

Microscopic evaluation showed no viable invasive cancer in 23 (85\%) of the 27 patients who had successful cryoablation. An additional four patients had ductal carcinoma-in-situ (DCIS) present within the normal tissue surrounding the cryozone. In two cases this was adjacent to the treatment zone, whereas in two cases this represented multifocal disease in the healthy tissue surrounding the ablation. The likelihood of success of cryoablation to leave no residual cancer cells was correlated with tumor size and histology (Table 3). Looking at size alone, of the 11 patients with tumors $<1.0 \mathrm{~cm}$ in size whose tumors were successfully ablated, all 11 had complete ablation of their cancer, with no residual invasive or intraductal carcinoma. Of the 16 patients with tumors $>1.0 \mathrm{~cm}, 10(63 \%)$ had neither residual invasive carcinoma or DCIS. 
TABLE 3. Correlation of tumor size and histology with successful cryoablation

\begin{tabular}{lcc}
\hline \multicolumn{1}{c}{ Treatment group } & $\begin{array}{c}\text { No. } \\
\text { Patients }\end{array}$ & $\begin{array}{c}\text { No residual invasive } \\
\text { or DCIS }\end{array}$ \\
\hline All patients & 27 & $21(78 \%)$ \\
Tumors $<1.0 \mathrm{~cm}$ (all histology) & 11 & $11(100 \%)$ \\
Tumors $>1.0 \mathrm{~cm}$ (all histology) & 16 & $10(63 \%)$ \\
Any size lobular or colloid & 5 & $2(40 \%)$ \\
Any size ductal with EIC & 5 & $3(60 \%)$ \\
Any size ductal or medullary, no EIC & 17 & $15(88 \%)$ \\
Tumors $<1.5 \mathrm{~cm}$; ductal or medullary, no EIC & 10 & $10(100 \%)$ \\
Tumors $>1.5 \mathrm{~cm}$; ductal or medullary, no EIC & 7 & $5(71 \%)$ \\
\hline
\end{tabular}

DCIS, ductal carcinoma-in-situ; EIC, extensive intraductal component.

${ }^{a}$ Excludes foci of DCIS found in healthy tissue surrounding the treatment zone.

Looking at histology, three patients with invasive lobular carcinoma and two with colloid carcinoma were treated. Three of these five had residual invasive cancer, and the final pathology demonstrated the tumor size to be significantly larger than predicted by pretreatment ultrasound. Five patients had invasive cancer and DCIS on core biopsy. Two of these patients had residual disease after cryoablation: DCIS alone located outside of the cryozone in one case and DCIS and invasive cancer at the treatment edge in the second case. There were 16 patients with invasive ductal carcinoma and 1 with medullary carcinoma. Of these 17 patients, 10 had tumors $<1.5 \mathrm{~cm}$. All 10 had complete ablation of their invasive cancer. One had a residual small focus of DCIS in the healthy tissue away from the cryozone. Of the seven patients with invasive ductal carcinoma $>1.5 \mathrm{~cm}$, five (71\%) had complete ablation of their cancer, one had residual invasive disease, and one had residual DCIS at the periphery.

\section{DISCUSSION}

The use of freezing temperatures to treat breast cancer is not a new concept. More than a century ago, irrigation devices were designed to bring iced saline solutions in contact with advanced breast tumors, resulting in the amelioration of pain and bleeding and a reduction in the size of the tumor. ${ }^{43-45}$ Since then there have been several advances in technology that expanded the applicability of cryosurgery in the treatment of solid tumors. In 1961, modern cryosurgery was made possible by the introduction of automated cryosurgical units that pump liquid nitrogen through the tip of an instrument, allowing the cryoablation of tumors at diverse sites, including the breast. Tanaka ${ }^{37}$ treated 49 patients with advanced or recurrent breast cancer with cryosurgery, reporting not only alleviation of pain, control of hemorrhage, and reduction of tumor bulk, but also a 5-year survival of $44.4 \%$ in this group of "incurable" patients. Rand et al. ${ }^{41,46}$ examined the use of cryotherapy performed in conjunction with surgical excision (cryolumpectomy) for early-stage cancer. Preclinical studies demonstrated that this reduced local recurrence, presumably by preventing the spillage or dissemination of tumor cells as a result of surgical manipulation. Staren et al. ${ }^{8}$ explored the concept of using cryoablation instead of lumpectomy to treat early-stage breast cancer. Both small- and large-animal studies demonstrated this to be both feasible and effective. One patient who opted for cryoablation instead of surgery remains recurrence free 7 years later. ${ }^{8,47}$

These results, and the potential benefit of cryosurgery in the treatment of early-stage breast cancer and development of an office-based treatment system, prompted a phase I multicenter trial of cryoablation followed by delayed surgical excision. The preliminary results from this multicenter trial highlight several issues. It is clear that cryoablation not only is clinically feasible, but also has minimal pain and morbidity. The subzero temperatures of the ice ball are naturally analgesic, so only local anesthesia is required for probe placement. Postprocedure discomfort was limited to mild edema, ecchymosis, and tenderness and was well controlled with over-thecounter medications. Tumor proximity to the skin is not a contraindication to cryoablation, particularly since the introduction of the $2.7-\mathrm{mm}$ vacuum-insulated cryoprobe. The ice ball is extremely well visualized by ultrasound, and the injection of sterile normal saline easily increases its distance from the skin. Hyperthermic ablation techniques, in contrast, require a skin distance of at least $1 \mathrm{~cm}$ to avoid the risk of skin injury, ${ }^{7,15}$ (AN Mirza et al., unpublished data) because inadvertent burns have complicated such techniques. ${ }^{5,14}$

In this study, all patients with tumors $<1.0 \mathrm{~cm}$ had complete $(100 \%)$ ablation of all breast cancer. All patients with tumors $<1.5 \mathrm{~cm}$, excluding those with invasive lobular or colloid carcinoma or significant DCIS, also had complete ablation (100\%) of all breast cancer. For tumors $>1.5 \mathrm{~cm}$, successful cryoablation was not 
predictable with these preoperative imaging techniques. These findings are similar to those described by Pfleiderer et al. ${ }^{9}$ in their report of 15 patients with primary breast tumors treated with cryosurgery. A $1.5-\mathrm{cm}$ size limit has also been recommended for the use of laser interstitial therapy and radiofrequency ablation. ${ }^{7,14}$

These results highlight that the key to ablative techniques is the ability to preoperatively identify truly unifocal lesions while being able to visualize both the tumor and the zone of destruction. With the limitations of mammography and ultrasonography, tumors without well-demarcated boundaries should not be treated by in situ ablation. Invasive lobular carcinomas are often multifocal or poorly defined on mammography and ultrasound, and the extent of the tumor may be substantially underestimated. ${ }^{49-51}$ Likewise, mucinous (colloid) carcinoma is often poorly defined on preoperative imaging. ${ }^{52,53}$ In this series, of the five patients with either lobular or mucinous cancer, three had residual invasive cancer after cryoablation.

On the basis of these results, we recommend that inclusion for a phase II study of cryoablation without surgical excision should be limited to patients with invasive ductal carcinoma $\leq 1.5 \mathrm{~cm}$ and with $<25 \%$ DCIS in the aggregate LCNBs. Although tumors $>1.5 \mathrm{~cm}$ may eventually be treated with cryoablation, perhaps by either placing more than one cryoprobe or repositioning the cryoprobe and performing a second ablation, it will be necessary to first define a population of patients who can be treated with simple central placement of a single cryoprobe. It is also possible that advances in the imaging techniques available today or those in development might be necessary for the preoperative selection of patients with more complicated breast cancer in the future.

The most challenging issue facing all ablative techniques is multifocal noncalcified DCIS. Every attempt should be made to exclude patients who may have a significant intraductal component. This includes evidence on LCNB and the presence of microcalcifications on mammography. ${ }^{54}$ The extent of microcalcifications on mammography often underestimates the histological size of DCIS, ${ }^{55,56}$ so all tumors with more than just the most minimal of calcifications present should also be excluded. However, there were four patients with no evidence of DCIS on core biopsy or diagnostic imaging who had DCIS in the periphery of the cryoablated zone. In two of these cases, this seemed to represent foci of DCIS in the healthy tissue away from the ablated cancer. These were detected on wide excision but would not have been identified if these cancers had been ablated without surgical excision. Today's gold standard for breast-conserving surgery requires the ability to assess the lumpectomy specimen margins, and, of course, tumor-free margins are required for subsequent optimal radiotherapy. Before in situ breast cancer ablation can become a mainstream therapy, the question of margin assessment will need to be addressed. With no specimen, how will margin clearance be ensured? Accurate and predictable preoperative imaging will be necessary to identify the full extent of disease.

Ultrasound today is unfortunately not accurate enough to predict the presence and extent of an intraductal component. ${ }^{57}$ Magnetic resonance imaging (MRI) has been to reported to more accurately diagnose the extent of an intraductal component than either mammogram or ultrasound. ${ }^{58}$ MRI has been shown to accurately define the extent of disease in breast cancer, including invasive lobular tumors, ${ }^{51,58}$ and has been used to guide ablative breast procedures. ${ }^{17,21,59}$ MRI may, therefore, play a future role in selecting patients appropriate for in situ ablation and/or assessing the efficacy of treatment. Further research will be necessary to address this issue.

Although there are several obstacles to overcome, given the potential benefits, there is significant motivation to identify whether cryoablation can replace lumpectomy in selected patients for the local treatment of small breast cancers. With the expanding use of screening mammography, the size of tumors at presentation is decreasing. Almost two thirds of women who present with breast cancer today will present with disease localized to the breast, ${ }^{1}$ and it has been predicted that by the year $2010,50 \%$ of newly diagnosed breast cancers may be $<1 \mathrm{~cm} .{ }^{60}$ That would represent 90,000 patients for whom a lumpectomy will be necessary, with the associated operating room time, anesthesia, cost, and cosmetic and psychological impact. Compared with lumpectomy, cryoablation can be performed in an office-based setting with no IV sedation. Cosmetically, cryosurgery has great esthetic appeal. It has long been known to cause minimal scarring when used in the treatment of cancers of the face, mouth, nose, and cervix. ${ }^{61}$ Cryoablation of benign fibroadenomas in the breast is performed with minimal scarring, outstanding cosmesis, and excellent patient satisfaction. ${ }^{38}$ Several months after cryosurgery, the cryotreatment site cannot be identified by ultrasound, mammogram, or MRI, and this has important consequences for surveillance. ${ }^{39,62}$

Finally, a unique aspect of cryosurgery that makes it particularly attractive for in situ ablation is the potential immunological benefit and the possibility that an immune response generated by the residual tumor protein material after ablation may be able to inhibit the growth of tumor foci distant from the primary tumor. ${ }^{63}$ The 
suggestion that a cryoimmunological benefit may exist initially came from clinical observations that patients being treated with cryosurgery showed evidence for an effect distant from the primary tumor. ${ }^{36,64-66}$ These observations prompted several laboratory and clinical studies that support the notion that cryosurgical destruction can augment the host's immune response to tumor tissue.36,67-77 Ongoing research is examining whether cryoablation of early-stage breast cancer will stimulate a clinically relevant immune response.

In conclusion, cryoablation can safely and efficiently treat small primary breast cancers. It can be performed in an office-based setting with only local anesthesia and with minimal side effects or discomfort. Ultrasound provides excellent visualization and control of the ablation and allows for adequate skin protection so that even tumors close to the skin can be treated without complications. Proper patient selection and probe placement is crucial to successful ablation. Patients with invasive breast cancer $<1.5 \mathrm{~cm}$ without invasive lobular or colloid cancers or an extensive intraductal component are good candidates for cryoablation. Assessing margin status and the presence of noncalcified DCIS in the healthyappearing tissue surrounding the tumor remains a dilemma for all ablative technologies. Further research is necessary to evaluate the most appropriate clinical use of cryoablation in the treatment of early-stage breast cancer.

\section{REFERENCES}

1. Jemal A, Tiwari RC, Murray T, et al. Cancer statistics 2004. $C A$ Cancer J Clin 2004;54:8-29.

2. Fisher B, Redmond C, Poisson R, et al. Eight-year results of a randomized clinical trial comparing total mastectomy and lumpectomy with or without irradiation in the treatment of breast cancer. N Engl J Med 1989;320:822-8.

3. Cady B, Stone MD, Schuler JG, et al. The new era in breast cancer: invasion, size and nodal involvement dramatically decreasing as a result of mammographic screening. Arch Surg 1996;131:301-8.

4. Jeffrey SS, Birdwell RL, Ikeda DM, et al. Radiofrequency ablation of breast cancer. First report of an emerging technology. Arch Surg 1999;134:1064-8.

5. Izzo F, Thomas R, Delrio $\mathrm{P}$, et al. Radiofrequency ablation in patients with primary breast carcinoma. A pilot study in 26 patients. Cancer 2001;92:2036-44.

6. Singletary SE. Minimally invasive ablation techniques in breast cancer treatment (editorial). Ann Surg Oncol 2002;9:319-20.

7. Singletary SE, Fornage BD, Sneige N, et al. Radiofrequency ablation of early-stage invasive breast tumors: an overview. Cancer $J$ 2002;8:177-80.

8. Staren ED, Sabel MS, Gianakakis LM, et al. Cryosurgery of breast cancer. Arch Surg 1997;132:28-33.

9. Pfleiderer SO, Freesmeyer MG, Marx C, et al. Cryotherapy of breast cancer under ultrasound guidance: initial results and limitations. Eur Radiol 2002;12:3009-14.

10. Robinson DS, Parel J-M, Denham DB, et al. Interstitial laser hyperthermia model development for minimally invasive therapy of breast carcinoma. J Am Coll Surg 1998;186:284-92.

11. Robinson DS, Parel J-M, Denham DB, et al. Stereotactic uses beyond core biopsy: model development for minimally invasive treatment of breast cancer through interstitial laser hyperthermia. Am Surg 1996;62:117-8.

12. Harries SA, Amin Z, Smith ME, et al. Interstitial laser photocoagulation as a treatment for breast cancer. Br J Surg 1994;81: 1617-9.

13. Dowlatshahi K, Bauich D, Kluiber R. Histologic evaluation of rat mammary tumor necrosis by interstitial Nd:YAG laser hyperthermia. Lasers Surg Med 1992;12:159-64.

14. Dowlatshahi K, Fan M, Gould VE, et al. Stereotactically guided laser therapy of occult breast tumors: work in progress report. Arch Surg 2000;135:1345-52.

15. Dowlatshahi K, Francescatti DS, Bloom KJ. Laser therapy for small breast cancers. Am J Surg 2002;184:359-63.

16. Mumtaz H, Hall-Graggs MA, Wotherspoon A, et al. Laser therapy for breast cancer: MR imaging and histopathologic correlation. Radiology 1996;200:651-8.

17. Harms SE. MR-guided minimally invasive procedures. Magn Reson Imaging Clin N Am 2001;9:381-92.

18. Hill CR, ter Haar GR. High intensity focused ultrasound-potential for cancer treatment. Br J Radiol 1995;68:1296-303.

19. ter Haar GR. Ultrasound focal beam surgery. Ultrasound Med Biol 1995;21:1089-100.

20. Bohris C, Jenne JW, Rastert R, et al. MR monitoring of focused ultrasound surgery (FUS) in a breast tissue model. Magn Reson Imaging 2001;19:167-75.

21. Hynynen K, Darkazanli A, Unger E, Schenck JF. MRI-guided noninvasive ultrasound surgery. Med Phys 1993;20:107-15.

22. Chung AH, Jolesz FA, Hynyen K. Thermal dosimetry of a focused ultrasound beam in vivo by magnetic resonance imaging. Med Phys 1999;26:2017-26.

23. Graham SJ, Chen L, Leitch M, et al. Quantifying tissue damage due to focused ultrasound heating observed by MRI. Magn Reson Med 1999;41:321-8.

24. Hynynen K, Pomeroy O, Smith DN, et al. MR Imaging-guided focused ultrasound surgery of fibroadenomas in the breast: a feasibility study. Radiology 2001;219:176-85.

25. Huber PE, Jenne JW, Rastert R, et al. A new non-invasive approach in breast cancer therapy using magnetic resonance imaging guided focused ultrasound surgery. Cancer Res 2001;61:8441-7.

26. Chaudhary SS, Mishra RK, Swarup A, Thomas JM. Dielectric properties of normal and malignant human breast tissue at radiowave and microwave frequencies. Indian J Biochem Biophys 1984; 21:76-9.

27. Joines WT, Zhang Y, Li C, Jirtle RL. The measured electrical properties of normal and malignant human tissues from 50 to 900 MHz. Med Phys 1994;21:547-50.

28. Campbell AM, Land DV. Dielectric properties of female human breast tissue measured in vitro at 3.2 GHz. Phys Med Biol 1992; 37:193-210.

29. Gardner RA, Vargas HI, Block JB, et al. Focused microwave phased array thermotherapy for primary breast cancer. Ann Surg Oncol 2002;9:326-32.

30. Ravikumar TS. The role of cryotherapy in the management of patients with liver tumors. Adv Surg 1997;30:281-91.

31. Weaver ML, Ashton JG, Zemel R. Treatment of colorectal liver metastases by cryotherapy. Semin Surg Oncol 1998;14:167-70.

32. Gage AA, Huben R. Cryosurgical ablation of the prostate. Urol Oncol 2000;5:11-9.

33. Onik GM, Cohen J, Reyes G, et al. Transrectal ultrasound-guided percutaneous radical cryoablation of the prostate. Cancer 1993;72: 1291-9.

34. Uchida M, Imaide Y, Sugimoto K, et al. Percutaneous cryosurgery for renal tumors. Br J Urol 1995;75:132-5.

35. Rukstalis D, Khorsandi M, Garcia F, et al. Clinical experience with renal cryoablation. Urology 2001;57:34-9.

36. Suzuki Y. Cryosurgical treatment of advanced breast cancer and cryoimmunological responses. Skin Cancer 1995;10:19-26. 
37. Tanaka S. Cryosurgical treatment of advanced breast cancer. Skin Cancer 1995;10:9-18.

38. Kaufman CS, Bachman B, Littrup PJ, et al. Office-based ultrasound-guided cryoablation of breast fibroadenomas. Am J Surg 2002;184:394-400.

39. Rabin Y, Julian TB, Olson P, et al. Long-term follow-up postcryosurgery in a sheep breast model. Cryobiology 1999;39:29-46.

40. Rui J, Tatsutani KN, Dahiya R, Rubinsky B. Effect of thermal variables on human breast cancer in cryosurgery. Breast Cancer Res Treat 1999;53:185-92.

41. Rand RW, Rand RP, Eggerding FA, et al. Cryolumpectomy for breast cancer: an experimental study. Cryobiology 1985;22:30718.

42. Neel HB, Ketcham AS, Hammond WG. Requisites for successful cryogenic surgery of cancer. Arch Surg 1971;102:45-8.

43. Gage AA. History of cryosurgery. Semin Surg Oncol 1998;14:99109.

44. Bird HM. James Arnott, MD (Aberdeen, 1797-1883): a pioneer in refrigeration analgesia. Anesthesia 1949;4:10-7.

45. Arnott J. Practical illustrations of the remedial efficacy of a very low or anesthetic temperature. Lancet 1850;2:257-9.

46. Rand RW, Rand RP, Eggerding F, et al. Cryolumpectomy for carcinoma of the breast. Surg Gynecol Obstet 1987;165:392-6.

47. Simmons R, Dowlatshahi K, Singletary SE, Staren ED. Imageguided ablation of breast tumors. Contemp Surg 2002;58:61-71.

48. Deleted in proof.

49. Helvie MA, Paramagul C, Oberman HA, Adler DD. Invasive lobular carcinoma: imaging features and clinical detection. Invest Radiol 1993;28:202-7.

50. Krecke KN, Gisvold JJ. Invasive lobular carcinoma of the breast: mammographic findings and extent of disease at diagnosis in 183 patients. AJR Am J Roentgenol 1993;61:957-60.

51. Munot K, Dall B, Achuthan R, et al. Role of magnetic resonance imaging in the diagnosis and single-stage surgical resection of invasive lobular carcinoma of the breast. Br J Surg 2002;89:1296301.

52. Chopra S, Evans AJ, Pinder SE, et al. Pure mucinous breast cancer-mammographic and ultrasound findings. Clin Radiol 1996;51:421-4.

53. Wilson TE, Helvie MA, Oberman HA, et al. Pure and mixed mucinous carcinoma of the breast: pathological basis for differences in mammographic appearance. AJR Am J Roentgenol 1995; $165: 285-9$

54. Stomper PC, Connolly JL. Mammographic features predicting an extensive intraductal component in early stage infiltrating ductal carcinoma. AJR Am J Roentgenol 1992;158:269-72.

55. Satake H, Shimamoto K, Sawaki A, et al. Role of ultrasonography in the detection of intraductal spread of breast cancer: correlation with pathologic findings, mammography and MR imaging. Eur Radiol 2000;10:1726-32.

56. Holland R, Hendriks JH, Verbeek A, et al. Extent, distribution, and mammographic/histologic correlations of breast ductal carcinoma in situ. Lancet 1990;335:519-22.

57. Tresserra F, Feu J, Grases PJ, et al. Assessment of breast cancer size: sonographic and pathologic correlation. J Clin Ultrasound 1999;27:485-91.
58. Boetes C, Mus RD, Holland R, et al. Breast tumors: comparative accuracy of MR imaging relative to mammography and US for demonstrating extent. Radiology 1995;197:743-7.

59. Deleted in proof.

60. Cady B. Breast cancer in the third millennium. Breast $J$ 2000;6: $280-7$.

61. Shepherd JP, Dawber RPR. Wound healing and scarring after cryosurgery. Cryobiology 1984;21:157-69.

62. Deleted in proof.

63. Johnson JP. Immunologic aspects of cryosurgery: potential modulation of immune recognition and effector cell maturation. Clin Dermatol 1990;8:39-47.

64. Gage AA. Cryosurgery for oral and pharyngeal carcinoma. Am J Surg 1969;118:669-72.

65. Soanes WA, Ablin RJ, Gonder MJ. Remission of metastatic lesions following cryosurgery in prostatic cancer. J Urol 1970;104:154-9.

66. Ablin RJ. An appreciation and realization of the concept of cryoimmunology. In: Ablin RJ, ed. Percutaneous Prostate Cryoablation. St. Louis: Quality Medical Publishing Inc, 1995:136-54.

67. Bayjoo P, Rees RC, Goepel JR, Jacob G. Natural killer cell activity following cryosurgery of normal and tumour bearing liver in an animal model. J Clin Lab Immunol 1991;35:129-32.

68. Bilchik AJ, Sarantou T, Wardlaw JC, Ramming KP. Cryosurgery causes a profound reduction in tumor markers in hepatoma and noncolorectal hepatic metastases. Am Surg 1997;63:796-800.

69. Faraci RP, Bagley DH, Marrone JC, Beazley RM. The effect of curative cryosurgery on the tumor-specific immune response of C57 mice. Cryobiology 1975;12:175-9.

70. Fazio M, Airoldi M, Gandolfo S, et al. Humoral and cellular immune response to cryosurgery of benign and malignant lesions of the oral cavity (in Italian). Boll Soc Ital Biol Sper 1982;58: 412-8.

71. Faraci RP, Bagley DH, Marrone JC, Beazley RM. In vitro determination of cryosurgical augmentation of tumor immunity. Surgery 1975;77:433-8.

72. Hoffmann NE, Coad JE, Huot CS, et al. Investigation of the mechanism and the effect of cryoimmunology in the Copenhagen rat. Cryobiology 2001;41:59-68.

73. Kogel H, Grundmann R, Fohlmeister I, Pichlmaier H. Cryotherapy of rectal cancer. Immunologic results (in German). Zentralbl Chir 1985;110:147-54.

74. Misao A, Sakata K, Saji S, Kuneida T. Late appearance of resistance to tumor rechallenge following cryosurgery: a study in an experimental mammary tumor of the rat. Cryobiology 1981;18: $386-9$.

75. Tsujino M. Activation and regulation of macrophages induced by inoculation of cryodestroyed tumor cells (in Japanese). Osaka Daigaku Shigaku Zasshi 1990;35:180-205.

76. Wang Z. Cryosurgery in rectal carcinoma-report of 41 cases (in Chinese). Zhonghua Zhong Liu Za Zhi 1989;11:226-7.

77. Ravindranath MH, Wood TF, Soh D, et al. Cryosurgical ablation of liver tumors in colon cancer patients increases the serum total ganglioside level and then selectively augments antiganglioside IgM. Cryobiology 2002;45:10-21. 